\title{
Epidemiology of iliopsoas haematoma in patients with haemophilia
}

\author{
HA Caviglia ${ }^{1,2}$, ME Landro*1, P Salgado ${ }^{1}$, AL Douglas Price ${ }^{1}$, C Daffunchio $^{1,2}$, D Neme ${ }^{2}$ \\ ${ }^{1}$ Juan A. Fernández General Hospital, Orthopaedic and Traumatology Department, Buenos Aires, Argentina \\ ${ }^{2}$ Foundation of Haemophilia, Buenos Aires, Argentina
}

Received: August 30, 2015

DOI: $10.5430 /$ jer.v2n2p18
Accepted: December 8, $2015 \quad$ Online Published: December 14, 2015

URL: http://dx.doi.org/10.5430/jer.v2n2p18

\begin{abstract}
Aim: Iliopsoas Haemorrhage (IPH) is a well-recognized complication of haemophilia. The aim of this paper is to show the current epidemiology of IPH in patients with haemophilia (PWH) treated at Argentinean Haemophilia Foundation, and observe the evolution of the treatment of the disease over the years.

Patients and methods: The 1995 series included 109 PWH with 223 episodes of IPH. Eighty-six (80.4\%) patients had Haemophilia A and twenty-one (19.6\%) had Haemophilia B, mean age was 18 years old. The 2008-2013 series included thirty-six PWH with sixty-five episodes of IPH. Twenty-nine (80.6\%) patients with Haemophilia A and seven patients (19.4\%) with Haemophilia B, all were severe. Seven patients with inhibitors and Haemophilia A, mean age was 22.1 years old.

Results: We found statistically significant differences between relation to the age ( $p$ : .003). In 2008-2013 series all patients had severe Haemophilia (100\%). Only eleven (30.6\%) patients presented previous IPH. In the pre 1995 series, twelve (12.1\%) were mild, forty $(40.4 \%)$ moderate and forty-seven $(47.5 \%)$ severe. Forty-nine (45.8\%) patients presented previous IPH. We only found statistically significant differences when comparing the degree of the disease between series ( $p$ : .001).

Conclusion: The usage of clotting factor concentrates, prophylactic therapy protocols by patients have contributed to increase the age of appearance IPH and decreased the prevalence rate of this pathology.
\end{abstract}

Key Words: Iliopsoas, Haematoma, Bleeding episodes, Haemophilia, Haemorrhage, Pelvic pseudotumor

\section{INTRODUCTION}

Muscle bleeds are the second most common type of bleed to haermathrosis. ${ }^{[1]}$ Iliopsoas haemorrhages (IPH) are a wellrecognized complication of haemophilia with significant associated morbidity ${ }^{[1-5]}$.

In patients with haemophilia (PWH) IPHs usually produce fibrillary muscle tears, unless they are treated early with factor replacement, in which case they behave clinically like muscular elongation. ${ }^{[6]}$
Patients whose haemorrhages are not treated early develop major injuries such as muscle tears. Treatment generally involves hospitalization, rest position with the muscle relaxed and factor replacement therapy with continuous infusion. ${ }^{[7]}$ When the bleeding episode is profuse a cyst may occur and eventually develop into a pseudotumour (PS). Pseudotumour growth may erode the iliac bone or cause skin necrosis due to pressure ${ }^{[8]}$ Pseudotumours may also expand into the lumbar region or cause a colon fistula. ${ }^{[7]}$ Pseudotumors can became infected due to colon or skin fistulas, with increased

*Correspondence: ME Landro; Email: mlandro@gmail.com; Address: Orthopaedic and Traumatology Department, General Hospital, Cerviño 3356, CABA, Argentina. 
life risk. ${ }^{[7]}$ Muscle bleeding induces a local inflammatory response, which may ultimately lead to fibrosis and muscle contracture and result in mechanical dysfunction, thus inducing further muscle bleeds. Iliopsoas Haematomas may also evolve into posttraumatic fibrosis, serum haematic cyst and muscular calcification. ${ }^{[9]}$ So it is important that the haematoma heal completely.

There are not many publications on epidemiology of IPHs in PWH. ${ }^{[3-5,9]}$ The aim of this paper is to show the current epidemiology of IPHs in PWH treated at the Argentinean Haemophilia Foundation, and to review the evolution of the treatment of the disease and how this affected the incidence of new cases of IPHs.

\section{Patients and methods}

We compared two series of PWH with IPHs.

The first series included $109 \mathrm{PWH}$ treated prior to 1995 for 223 episodes of IPHs. One hundred and sixty (52.5\%) were right sided and 105 (47.5\%) were left sided. Eighty-six (80.4\%) patients had Haemophilia A and twenty-one (19.6\%) had Haemophilia B, mean age was 18 years old (16-50 years old).

The second group studied includes patients treated at the Argentinean Haemophilia Foundation between 2008-2013. Thirty-six PWH with sixty-five episodes of IPHs, thirty-five $(53.8 \%)$ were right sided and thirty $(46.2 \%)$ were left sided. Twenty-nine $(80.6 \%)$ patients had Haemophilia A and seven patients $(19.4 \%$ ) had Haemophilia B, all were severe. Seven patients had inhibitors and all were type A, mean age was 22.1 years old (9-42 years old).
We evaluated age, clinical signs, number of bleeding episodes (BE), side, type and degree of Haemophilia.

\section{Statistical analysis}

In order to describe the qualitative variables the frequencies and percentages were calculated. On the other hand, the mean, median, standard deviation, minimum and maximum were estimated for quantitative variables. With the purpose of comparing the relationship between qualitative variables it was carried out a test of independence (Chi square) and comparison of proportions for independent samples was used. In the case of quantitative variables with factors or groups, $t$-Student tests for independent samples were used.

Statistical tests for independent samples and a level of significance (Type-I error) at most of 5\% were applied in all cases.

\section{Results}

One hundred and nine PWH (10\% of 1,079) treated at the Argentinean Haemophilia Foundation seen prior to 1995 had IPHs. Thirty-six PWH (1.54\% of 2,327) treated at the same place until the end of 2013 had IPHs. We found statistically significant differences ( $p$ : .001) (see Table 1).

Table 1. Iliopsoas Haematoma (IPH) prevalence in Patients with haemophilia (PWH)

\begin{tabular}{llll}
\hline Series & 2008-2013 & pre 1995 & $\boldsymbol{P}$ \\
\hline Patients with IPH & 36 & 107 & $* .001$ \\
Total PWH & 2,327 & 1,079 & \\
$\%$ & $1.54 \%$ & $10.0 \%$ & \\
\hline
\end{tabular}

* Statistically significant differences

Table 2. Comparative results between 2008-2013 and 1995 series

\begin{tabular}{|c|c|c|c|c|c|c|}
\hline \multirow{2}{*}{$\begin{array}{l}\text { Series } \\
\text { Variable }\end{array}$} & & \multicolumn{2}{|l|}{ 2008-2013 } & \multicolumn{2}{|l|}{ pre 1995} & \multirow{2}{*}{$p$} \\
\hline & & Frequency & Percent & Frequency & Percent & \\
\hline \multirow{2}{*}{ Previous bleeding } & Yes & 11 & $30.6 \%$ & 49 & $45.8 \%$ & \multirow{2}{*}{.109} \\
\hline & No & 25 & $69.4 \%$ & 58 & $54.2 \%$ & \\
\hline \multirow{2}{*}{ Side } & Right & 35 & $53.8 \%$ & 116 & $52.5 \%$ & \multirow{2}{*}{.847} \\
\hline & Left & 30 & $46.2 \%$ & 105 & $47.5 \%$ & \\
\hline \multirow{2}{*}{ Type of haemophilia } & A & 29 & $80.6 \%$ & 86 & $80.4 \%$ & \multirow{2}{*}{.909} \\
\hline & B & 7 & $19.4 \%$ & 21 & $19.6 \%$ & \\
\hline \multirow{3}{*}{ Degree } & Mild & 0 & $0.0 \%$ & 12 & $12.1 \%$ & \multirow{3}{*}{.001} \\
\hline & Moderate & 0 & $0.0 \%$ & 40 & $40.4 \%$ & \\
\hline & Severe & 65 & $100.0 \%$ & 47 & $47.5 \%$ & \\
\hline
\end{tabular}


The mean age in each period was 18 years old and 22.1 years old prior 1995 and between 2008-3013 respectively. We found statistically significant differences ( $p$ : .003).

Table 2 shows the variables analyzed in each series. In the 2008-2013 series, twenty-nine patients were Haemophilia A (seven had inhibitors) and seven were Haemophilia B. All patients had severe Haemophilia (100\%). Only eleven $(30.6 \%)$ patients had already had IPHs. In the pre $1995 \mathrm{se}-$ ries eighty-six patients were Haemophilia A and twenty-one were Haemophilia B. Twelve were classified as mild (12.1\%), forty as moderate $(40.4 \%)$ and forty-seven as severe $(47.5 \%)$ Forty-nine $(45.8 \%)$ patients had previously IPH. We found no statistically significant differences between the number of patients with previous IPHs in these series ( $p$ : .847).

We only found statistically significant differences between the series when comparing the degree of the disease ( $p$ : $.001)$. The 2008-2013 series only had patients with severe haemophilia.

Clinical diagnosis was made with the following criteria: groin pain, hip flexion contracture and femoral sensitive sign.

In both series patients with IPHs had thigh, hip and/or groin pain $(100 \%)$, and hip flexion contracture (100\%). These signs are important to do the diagnostic for this complication. Femoral nerve paresthesia $(67.7 \%)$ was higher in the series 2008-2013 series than in series pre 1995 (34.38\%) series.

We found sixty-five BE in the $2008-2013$ series. Twenty-five patients had one BE, five had two BE, two had three BE, two had four $\mathrm{BE}$, one had seven $\mathrm{BE}$ and one had nine BE. In the pre 1995 series included 223 BE. Sixty patients had one BE, twenty had two BE, thirteen had three BE, four had four BE, seven had five $\mathrm{BE}$, two had six $\mathrm{BE}$ and three had seven $\mathrm{BE}$ (see Table 3).

Table 3. Bleeding episodes (BE) frequency

\begin{tabular}{lllll}
\hline Series & 2008-2013 & \multicolumn{3}{c}{ pre 1995 } \\
\hline Episodes & Patients & Total & Patients & Total \\
\hline 1 & 25 & 25 & 60 & 60 \\
2 & 5 & 10 & 20 & 40 \\
3 & 2 & 6 & 13 & 39 \\
4 & 2 & 8 & 4 & 16 \\
5 & 0 & 0 & 7 & 35 \\
6 & 0 & 0 & 2 & 12 \\
7 & 1 & 7 & 3 & 21 \\
9 & 1 & 9 & 0 & 0 \\
Total & 36 & 65 & 109 & 223 \\
\hline
\end{tabular}

The average BE per patients was 1.81 (1-9 BE) in the 20082013 series and 2.05 (1-7 BE) in the pre 1995 series. We found no statistically significant differences ( $p:$.189).

In the series 2008-2013 seven patients developed inhibitors against factor replacement therapy. Hospitalization duration averaged eight days (2-45 days). Mean hospitalization duration in patients with inhibitors (seven patients with twenty BE) was 10.45 days $(S D=8.953)$, and 6.78 days in patients without inhibitors $(S D=3.037)$ (twenty-nine patients with forty-five BE). This difference was statistically significant ( $p=.016)$. Bleeding episodes in inhibitors patients are more difficult to treat. Prior to 1995 inhibitors patients were not detected (see Table 4).

Table 4. Hospitalization duration in patients with inhibitors, with and without inhibitors

\begin{tabular}{lllll}
\hline Inhibitor & $\begin{array}{l}\text { Bleeding } \\
\text { Episodes }\end{array}$ & $\begin{array}{l}\text { Mean } \\
\text { Hospitalization } \\
\text { Duration (days) }\end{array}$ & $\begin{array}{l}\text { Standard } \\
\text { Desviation }\end{array}$ & $\boldsymbol{p}$ \\
\hline YES & 20 & 10.45 & 8.953 & .016 \\
NO & 45 & 6.78 & 3.037 & \\
\hline
\end{tabular}

Fifty-two (80\%) patients had completely recovered at the time of discharge and twelve (20\%) required additional outpatient physiotherapy under support factor replacement therapy.

\section{DiscUSSION}

Iliopsoas Haematoma in patients with haemophilia is a wellknown complication, that limits the functional capacity of the patient. Many publications describe this entity. ${ }^{[3-5]}$

In relation to occurrence of IPH in PWH treated in the Argentinean Haemophilia Foundation we found that in the 20082013 series was $1.54 \%$, thirty-six out of 2,327 patients and in the pre 1995 series was $10 \%, 109$ out of 1,079 patients. This is statistically significant ( $p$ : .001).

Turkey's series had eight patient with IPH out of 146 patients recorded between 1998 and 2005 and the occurrence was 5.47\%. [5] In Minnesota's series between 1972 and 2000 two $221 \mathrm{PWH}$ were recorded and twenty-eight presented IPH, the occurrence was $12.67 \% .{ }^{[4]}$ France's series had five patients with IPH out of 410 patients recorded between 2001 and 2005 and the occurrence was $1.2 \% .^{[10]}$

Argentina begun prophylaxis program to patients under eighteen years old (law approved in National Congress) in 2000. We believe this explains the increase in the mean age for the IPHs in 2008-2013 series. Before 2000, we had not yet implemented the patient education program and factor self-infusion was rare. Patients were hospitalized for IPHs 
treatment with continuous infusion. Patients were educated with self-infusion and received prompt treatment for $\mathrm{BE}$ in the 2008-2013 series. The widespread usage of clotting factor concentrates, prophylactic therapy protocols and selfadministration of factors by patients may have contributed to the decreased prevalence rate in our study.

Iliopsoas haematoma is a pathology that usually appears after adolescence. The mean age of patients with IPHs increased from 18 years old in pre 1995 series to 22 years old in 2008-2013 series ( $p$ : .003). Mean age was 21.9 years old in Minnesota's series, 16.9 years old in Turkish's series and 20.4 years old in France's series. ${ }^{[4,5,10]}$ This is consistent with beneficial effects of the introduction of prophylactic factor therapy, which may decrease the rate of bleeding episodes and increase the age of appearance.

The 2008-2013 series only included patients with severe haemophilia. In the pre 1995 series, 88 out of 109 patients (80.7\%) had Haemophilia A and 21(19.3\%) had Haemophilia B. Twelve $(12.1 \%)$ were mild, forty $(40.4 \%)$ were moderate and forty-seven $(47.5 \%)$ were severe. We found statistically significant differences when comparing the degree of the disease in the two Argentine series ( $p$ : .001). In Minnesota's series (1972-2000) nineteen out of twenty-eight patients (67.8\%) had Haemophilia A and nine (32.2\%) had Haemophilia B. ${ }^{[5]}$ Sixteen $(57.2 \%)$ were mild and moderate and twelve (42.8\%) were severe. In Turkey's series (19982005 ) six out of eight patients (75\%) had Haemophilia A and two $(25 \%)$ had Haemophilia B. ${ }^{[4]}$ One $(12.5 \%)$ was

\section{REFERENCES}

[1] Duthie RB. Muscle bleeds and consequences. In: Duthie R, Rizza C, Giangrande P, Dodd C, eds. The Management of Musculoskeletal Problems in the Hemophilia, 2nd edn. Oxford: Oxford University Press. 1994: 104-17.

[2] Alcalay M, Deplas A. Rheumatological management of patients with hemophilia. Part II: Muscle hematomas and pseudotumors. Joint Bone Spine. 2002; 69(6): 556-9. http://dx.doi.org/10.1016 /S1297-319X (02) 00451-7

[3] Fernandez-Palazzi F, Hernandez SR, DeBosch NB, et al. Hematomas within the iliopsoas muscles in hemophilic patients: the Latin American experience. Clin Orthop. 1996; 328: 19-24. http://dx.doi.o rg/10.1097/00003086-199607000-00005

[4] Balkan C, Kavakli K, Karapinar D. Iliopsoas haemorrhage in patients with haemophilia: results from one centre. Haemophilia. 2005; 11(5): 463-7. PMid:16128889 http://dx.doi.org/10.1111/j $.1365-2516.2005 .01123 . x$

[5] Ashrani AA, Osip J, Christie B, et al. Iliopsoas haemorrhage in patients with bleeding disorders-experience from one centre. Haemophilia. 2003; 9(6): 721-6. http://dx.doi .org/10.1046 /j.1351-8216.2003.00822.x

[6] Beyer R, Ingerslev J, Sørensen B. Muscle bleeds in professional athletes-diagnosis, classification, treatment and potential impact Published by Sciedu Press mild, one $(12.5 \%)$ was moderate and six $(75 \%)$ were severe. In France's series (2001-2005) included 5 patients with Haemophilia A (100\%). One (20\%) was moderate and four $(80 \%)$ were severe. ${ }^{[10]}$

The proportion of patients with haemophilia A and B remains unchanged in our two series. The lower IPHs rate in patients with haemophilia B in all series analyzed is consistent with the proportion of patients with Haemophilia type A and B in the general population.

Patients with IPHs had thigh, hip and/or groin pain (100\%), and hip flexion contracture $(100 \%)$. These signs are important to do the diagnostic for this complication. Femoral nerve paresthesia (67.7\%) was higher in the 2008-2013 series than in series pre 1995 (34.38\%) series. We believe this is because in the 2008-2013 series all patients had severe haemophilia, that leads in larger size haematomas resulting in more nerve compression. ${ }^{[11]}$ In addition, some patients had inhibitors, a further treatment complication.

\section{Conclusion}

The usage of clotting factor concentrates, prophylactic therapy protocols by patients have contributed to increase the age of appearance IPH and decreased the prevalence rate of this pathology. Early and effective factor replacement therapy in IPH is essential in the prevention of the complications such as, re-bleeding and development of pseudotumours in PWH.

\section{CONFLiCTS OF INTEREST Disclosure}

Authors declare they have no conflict of interest. in patients withhaemophilia. Haemophilia. 2010; 16(6): 858-65. PMid:20491962 http://dx.doi.org/10.1111/j.1365-2516. 2010.02278.x

[7] Caviglia H. In When does a repetitive bleed become a Pseudotumour? Formation and Management of Pelvic Pseudotumour. Session B. Repetitive Bleeds, Secondary Knee Damage \& the Development of Pelvic Pseudotumour. 11th International Musculoeskeletal Congress, Cartagena de Indias, Colombia. 2009: 30-32.

[8] Kamal AF, Pradana AS, Prabowo Y. Bilateral iliopsoas haemophilic "soft tissue pseudotumours": A case report. International Journal of Surgery Case Reports. 2015; 13: 19-23. PMid:26083481 http://dx.doi.org/10.1016/j.ijscr.2015.05.018

[9] Gilbert MS. Musculoskeletal manifestations of hemophilia. Mt Sinai J Med. 1977; 44: 339-58. PMid:302398

[10] Dauty M, Sigaud M, Trossaërt M, et al. Iliopsoas hematoma in patients with hemophilia: a single-center study. Joint Bone Spine. 2007; 74(2): 179-83. PMid:17336570 http://dx.doi.org/10.1016/j .jbspin.2006.05.014

[11] Chen LX, Hua BL, Liu Y, et al. Clinical characteristics and rehabilitation treatment of iliopsoas hemorrage in 41 patients with hemophilia. Zhonghua Xue Ye Xue Za Zhi. 2012; 33(5): 406-8. PMid:22781802 